\title{
ЗНАЧЕНИЕ ЦЕННОСТНЫХ ОРИЕНТАЦИЙ КАК ФАКТОРА В ФОРМИРОВАНИИ ОРГАНИЗАЦИОННОЙ КУЛЬТУРЫ И МЕЖКЛЬТУРНОГО ВЗАИМОДЕЙСТВИЯ В ОРГАНИЗАЦИЯХ ПРОИЗВОДСТВЕННОЙ СФЕРЫ РЕСПУБЛИКИ КРЫМ
}

\section{THE IMPORTANCE OF VALUE \\ ORIENTATIONS AS A FACTOR \\ IN THE FORMATION OF ORGANIZATIONAL \\ CULTURE AND INTERCULTURAL \\ INTERACTION IN THE ORGANIZATIONS \\ OF THE PRODUCTION SPHERE \\ OF THE REPUBLIC OF CRIMEA}

O. Korol

Summary: The article discusses and substantiates the author's position regarding the problem field of determination of the organizational culture of a modern organization. The results of the analysis of the nomenclature of value orientations, which determine the meaningful characteristics of organizational culture and intercultural interaction of employees of organizations in the production sector, are presented. This position may be of interest to specialists in the field of social psychology and organizational management.

Keywords: value orientations, organizational culture, organization, group, values.
Король Ольга Феликсовна

К.nсх.н., дочент, ГБОУ ВО Республики Крым «Крымский инженерно-педагогический университет им. Февзи Якубова», г. Симферополь korololga2008@gmail.com

Аннотация: В статье рассмотрена и обоснована позиция автора относительно проблемного поля детерминации организационной культуры современной организации. Представлены результаты анализа номенклатуры ценностных ориентаций, определяющей содержательные характеристики организационной культуры и межкультурного взаимодействия сотрудников организаций производственной сферы. Такая позиция может быть интересна специалистам в области социальной психологии и организационного управления.

Ключевые слова: межкультурное взаимодействие, ценностные ориентации, организационная культура, организация, группа, ценности.

\begin{abstract}
A ктуальность темы: Современный период в развитии Крымского региона отражает переход к новым динамичным процессам различных форм, связей и отношений социокультурного взаимодействия. Это не может находиться вне внимания ученых, обусловливая изучение не только прикладных аспектов, но и генерируя необходимость фундаментальных исследований. Наибольший интерес, в связи с этим, вызывает межкультурное взаимодействие, как способ совместного существования социальных структур системного порядка, характеризующихся интенсивным обменом информацией, ценностями, результатами деятельности и организационная культура, регулирующая сложный социально-психологический порядок межкультурного взаимодействия в коллективе организации.
\end{abstract}

Известно, что успех функционирования любого коллектива тесно связан с особым стилем взаимодействия между входящими в него личностями, точнее, со стандартизированными образцами, «опривыченными действиями» $[1$, с.50-72], стереотипами мышления и т.п., которые включены в более сложную регулятивную систему, какой является культура организации.

Вопрос организационной культуры не является новым и освещен в работах отечественных и зарубежных психологов [1;5-6;8-9;11;14-15]. Однако, из существующих определений организационной культуры, мы используем аксиологическую концепцию как имеющую наибольшие эвристические возможности для решения актуальных проблем межкультурного взаимодействия в современных организациях.

Объектом нашего исследования является культура организаций промышленной сферы, как система ценностей, фиксирующая общую направленность интересов всех её членов относительно конкретной сферы социальной активности, а предметом исследования - ценностные ориентации, регулирующие и определяющие тональность межкультурного взаимодействия в исследуемых коллективах. 
Целью нашей работы является выявление критериев, по которым можно судить о роли ценностных ориентаций в становлении организационной культуры, ее влияния на эффективность межкультурного взаимодействия в организациях промышленной сферы. Нами сделана попытка показать возрастающую роль организационной культуры во внедрении изменений и в развитии коллективов данной сферы деятельности, а так же наметить некоторые дальнейшие пути освещения этой темы в связи с эффективностью межкультурного взаимодействия в организациях.

\section{Из^ожение основного материала}

Отметим, что изучение организационной культуры началось сравнительно недавно (70 - 80 года XX века) под влияние культурологического подхода, имеющего в основе и функционалистические традиции (Б. Млиновский), и социологические (Э. Дюргейм), и исследования организационного климата в психологии (В.В. Бойко, Р.Л. Кричесвский, К. Левин, Л.Г. Почебут, В.А. Чикер)[ цит по 16, с.110-115].

Согласно классику организационной культуры Э. Шейна, с деятельностью которого связаны основные достижения в этой области и в настоящее время, «культура - паттерн (шаблон, схема, модель, рамки) коллективных базовых представлений, обретаемых группой при разрешении проблем адаптации к изменениям внешней среды и внутренней интеграции, эффективность которого оказывается достаточной для того, чтобы считать его ценным и передавать новым членам группы в качестве правильной системы восприятия и рассмотрения названных проблем» [15, с.31-32].

В очевидном разнообразии определений и толкований организационной культуры, можно выделить и общие моменты [8, с.15-25]. Во-первых, в большинстве определений авторы ссылаются на образцы базовых представлений, которые являют собой регламентированные стандарты поведения и деятельности, воспроизводимые в неизменном виде в течение длительного времени всеми членами коллектива. Во-вторых, характеристикой организационной культуры считаются ценности (или ценностные ориентации), пронизывающие всю культуру коллектива и обуславливающие избирательный подход не только к вновь созданным ценностям, но и к ценностям «чужой» социальной группы. И, в-третьих, к атрибутам организационной культуры авторы относят символику. Фиксируясь в явлениях и вещах, общественные идеалы приобретают способность передаваться во времени и усваиваться людьми. Именно через атрибут, который можно подвергнуть ценностному измерению фиксируется, накапливается и передается жизненно важный опыт проявлений социального свойства.
Ценностные ориентации как идеалы, или «модели должного»[5;9;14], являясь определяющими в поведении коллектива и личности в нем, задают спектр инвариантных желательных преобразований взаимодействия в совместной деятельности, мобилизуя жизненные силы и способности членов коллектива.

Мы проводили исследование ценностных ориентаций как фактора в формировании организационной культуры и межкультурного взаимодействия в организация промышленной сферы.

Представление о перечне ценностных ориентаций мы получили, рассматривая два вида структур ценностных ориентаций: иерархической структуры ценностных ориентаций, которая определялась через ранжирование личностью жизненных ценностей, традиционно исследованных в работах М. Рокича, В.А. Ядова и других [17; 20] и корреляционной структуры. Необходимость рассмотрения корреляционной структуры ценностных ориентаций обусловлена тем, что те или иные ценности могут иметь один вес, быть равнозначными для личности, то есть не существовать в иерархических отношениях между собой. Прежде всего, это может касаться не основных (второстепенных, менее значимых, расположенных ниже в иерархии) ценностей.

Для определения перечня ценностных ориентаций испытуемых, и для анализа ценностной структуры и соотношения в ней терминальных и инструментальных ценностей нами была использована методика М. Рокича «Ценностные ориентации» [13, с.637-641]. Известно, что М. Рокич, определяя ценность «как устойчивое убеждение в том, что определенный способ поведения или конечная цель существования наиболее важна с личной и социальной точек зрения, чем противоположный или обратный способ поведения» [там же, с.637], разделил ценности на два класса. Первый - это терминальные ценности, то есть убеждения в том, что какая-то конечная цель индивидуального поведения стоит того, чтобы к ней стремиться. И второй - это инструментальные ценности, или убеждение в том, что какой-то образ действия или свойство личности является предпочтительным в любой соответствующей ситуации.

Рассмотрим результаты эмпирического исследования. Иерархическая структура ценностных ориентаций предполагает изучение степени (уровня) выраженности измеряемого признака. В таблицах 1.1 и 1.2 нами представлены средние значения (Mx), всех терминальных и инструментальных ценностей в организациях производственной сферы.

Кроме того, с помощью критерия U - Манна-Уитни (Mann-Whitney U) мы определяли, насколько пересекаются наблюдаемые значения по шкалам теста М. Рокича 
у испытуемых в организациях производственной сферы (промышленность) (група1) и организациях промышленной сферы (строительство) (группа 2). В результате, при сравнении двух выборочных средних, были получены значение уровня статистической значимости * $\mathrm{p}<0,05$; ** $\mathrm{p}<0,01{ }^{* * *} \mathrm{p}<0,001$ (Таблица 1.1.).

В результате, по шкале «Терминальные ценности» диапазон наиболее значимых (приоритетных) Т-ценностей (высокие показатели средних значений) у сотрудников промышленных организаций (группа1) включает: «здоровье» $(\mathrm{Mx}=15,32)$, «счастливая семейная жизнь» $(M x=13,16)$, «интересная работа» $(M x=13,10)$, «материально обеспеченная жизнь» $(\mathrm{Mx}=12,97)$, «любовь» $(M x=12,54)$, «наличие надежных и верных друзей» $(M \mathrm{x}=12,21)$. У сотрудников строительных организаций (группа 2), в этом же диапазоне мы наблюдаем такие ценностные ориентации, как: «здоровье» $(M x=13,02)$, «счастливая семейная жизнь» $(\mathrm{Mx}=12,56)$, «интересная работа» (Mx 11,44), «любовь» $(M x=11,21)$, «наличие надежных и

Таблица 1.1.

Различия между показателями характеристики Т-ценностей «терминальные ценности» шкал теста М. Рокича в организациях производственной сферы (группа 1 - промышленность), (группа 2 - строительство)

\begin{tabular}{|c|c|c|c|c|}
\hline \multirow{2}{*}{ Терминальные ценности (ценности-цели) } & \multicolumn{2}{|c|}{ Группа 1} & \multicolumn{2}{|c|}{ Группа 2} \\
\hline & Mx, Md & $\pm S x$ & $\mathrm{Mx}, \mathrm{Md}$ & $\pm S x$ \\
\hline Здоровье & $\begin{array}{c}15,32 \\
17,0\end{array}$ & $\pm 0,41$ & $\begin{array}{c}13,02 \\
16,0\end{array}$ & $\pm 0,47$ \\
\hline Счастливая семейная жизнь & $\begin{array}{c}13,16 \\
15,0\end{array}$ & $\pm 0,48$ & $\begin{array}{c}12,56 \\
14,0\end{array}$ & $\pm 0,38$ \\
\hline Интересная работа & $\begin{array}{c}13,10 \\
14,0\end{array}$ & $\pm 0,40$ & $\begin{array}{c}11,44 \\
13,0\end{array}$ & $\pm 0,35$ \\
\hline Материально обеспеченная жизнь & $\begin{array}{c}12,97 \\
14,0\end{array}$ & $\pm 0,36$ & $\begin{array}{c}10,58 \\
12,0\end{array}$ & $\pm 0,41$ \\
\hline Любовь & $\begin{array}{c}12,54 \\
14,0\end{array}$ & $\pm 0,46$ & $\begin{array}{c}11,21 \\
12,5\end{array}$ & $\pm 0,40$ \\
\hline Наличие надёжных и верных друзей & $\begin{array}{c}12,21 \\
13,5\end{array}$ & $\pm 0,41$ & $\begin{array}{c}11,10 \\
12,0\end{array}$ & $\pm 0,33$ \\
\hline
\end{tabular}

Таблица 1.2.

Различия между показателями характеристики «инструментальные ценности» шкал теста М. Рокича в организациях производственной сферы.

\begin{tabular}{|c|c|c|c|c|}
\hline \multirow{2}{*}{$\begin{array}{l}\text { Инструментальные ценности } \\
\text { (ценности-способы) }\end{array}$} & \multicolumn{2}{|c|}{ Группа 1} & \multicolumn{2}{|c|}{ Группа 2} \\
\hline & $M x, M d$ & $\pm S x$ & $\mathrm{Mx}, \mathrm{Md}$ & $\pm S x$ \\
\hline Образованность & $\begin{array}{c}11,78 \\
13,0 \\
\end{array}$ & $\pm 0,45$ & $\begin{array}{r}11,97 \\
13,0 \\
\end{array}$ & $\pm 0,36$ \\
\hline Ответственность & $\begin{array}{r}11,75 \\
12,0 \\
\end{array}$ & $\pm 0,45$ & $\begin{array}{c}12,91 \\
14,0 \\
\end{array}$ & $\pm 0,35$ \\
\hline Воспитанность & $\begin{array}{c}11,66 \\
12,0\end{array}$ & $\pm 0,44$ & $\begin{array}{c}11,28 \\
12,0\end{array}$ & $\pm 0,38$ \\
\hline Аккуратность & $\begin{array}{c}11,47 \\
12,0\end{array}$ & $\pm 0,47$ & $\begin{array}{c}10,74 \\
12,0\end{array}$ & $\pm 0,41$ \\
\hline Жизнерадостность & $\begin{array}{c}11,32 \\
12,0 \\
\end{array}$ & $\pm 0,48$ & $\begin{array}{c}9,19 \\
9,0\end{array}$ & $\pm 0,39$ \\
\hline Независимость & $\begin{array}{r}11,15 \\
12,0 \\
\end{array}$ & $\pm 0,48$ & $\begin{array}{c}9,42 \\
9,0 \\
\end{array}$ & $\pm 0,39$ \\
\hline Честность & $\begin{array}{c}10,29 \\
10,0\end{array}$ & $\pm 0,50$ & $\begin{array}{l}11,47 \\
12,0\end{array}$ & $\pm 0,42$ \\
\hline Рационализм & $\begin{array}{c}10,10 \\
10,5 \\
\end{array}$ & $\pm 0,48$ & $\begin{array}{c}11,13 \\
12,0 \\
\end{array}$ & $\pm 0,35$ \\
\hline
\end{tabular}


верных друзей» $(\mathrm{Mx}=11,10)$

По шкале «инструментальные ценности» (И-ценности), по аналогии с предыдущим, в список ценностных ориентаций, имеющих сильное преимущество у сотрудников промышленных организаций, включены: «образованность» $(M x=11,78)$, «ответственность» $(M x=11,75)$, «воспитанность» $(M x=11,66)$, «аккуратность» $(M x=11,47)$, «жизнерадостность» $(M x=11,32)$ и «независимость» $(M \mathrm{X}=11,15)$. До этого же диапазона в организации строительной компании относятся: «ответственность» $(M x=12,91)$, «образованность» $(M x=11,97)$, «честность» $(M x=11,47)$, «воспитанность» $(M x=11,28)$, «рационализм» $(M x=11,13)$ и «аккуратность» $(M x=10,47)$.

Вышеотмеченные характеристики дают возможность понять модель отношений между содержанием культуры организации, ее проявлением и восприятием, и интерпретацией этой культуры работниками. Разделяя веру и ожидания, вырабатывая язык общения, проявляя понимание в чувствах и эмоциях, решая ежедневно проблемы, связанные с работой и жизнью организации, члены коллектива формирую определенные образцы поведения в межкультурном взаимодействии, которые затем и составляют содержание организационной культуры.

Далее, в исследовании параметров организационной культуры мы опирались на концепцию Г. Хофстида и Д. Боллинже, которые выделяют следующие переменные: дистанцию власти, индивидуализм, мужественность, стремление избежать неопределенность, долгосрочность ориентаций [19, с.7].

Согласно мнений респондентов, параметр «дистанция власти», определяющий степень неравенства между членами коллектива, имеет завышенное значение (80\%). Большинство сотрудников рассматривают своих руководителей как «других» людей (89\%), что свидетельствует о тенденции к централизации управленческих функций, этому факту мы находим подтверждение и в наличии 70\% управляюще-контролирующих сотрудников нашей выборки, отмечающих дифференциацию заработной платы (67\%).

Параметр «индивидуализм» имеет среднее значение (69\%) и характеризует степень самостоятельности членов коллектива и их ответственности за принятые решения. Анализ данных по этому показателю подтверждает, что 90\% респондентов могут надеяться только на себя, 85\% -характеризуют социальные связи внутри организаций достаточно дистанционными, 87\% - считают важным работать в коллективах, в котором люди хорошо взаимодействуют друг с другом, а отношения между администрацией и коллективом основываются преимущественно на учете личного вклада сотрудника (67\%).

В результате анализа данных по параметру «тенденция к избежанию неопределенности» было выявлено, что высокая степень стремления избегать риска, проявление беспокойства, лихорадочности в работе, «авральность» отмечают 91\% респондентов, неготовность к новой работе и боязнь неуспеха, а, следовательно, и сопротивление изменениям проявляют 86\% опрошенных. Исходя из вышеизложенного, можно заключить, что предпочтение в исследуемых коллективах оказывают структурированным ситуациям, с ясными и четкими правилами взаимодействия, избегая неопределенности и нововведений.

Оценка параметра долгосрочности ориентаций характеризуется низкой степенью проявления (43\%). Так, например, взглядом в будущее, стремлением, упорством и настойчивостью в достижении целей отличаются только 29\% респондентов, 70\% из них характеризуются взглядом в прошлое, беспокоятся за благополучие и обеспеченность в настоящем.

Итак, обобщая изложенное, можно сделать вывод о том, что организационная культура посредством доминирующих в ней ценностей закрепляет общие принципы построения межкультурного взаимодействия в коллективе и определяет вектор его развития.

\section{ЛИТЕРАТУРА}

1. Бергер П. Социальное конструирование реальности: трактат по социологии знания / П. Бергер, Т. Лукман. - М.: Медиум, 1995. С. 89 - 92.

2. Виханский, 0.С. «Другой» менеджмент: время перемен / О.С. Виханский, А.И. Наумов // Российский журнал менеджмента. — 2004. — Т. 2. № 3. — C.105-126.

3. Журавлев, А.Л. Социально-психологические факторы обмена знаниями в организации / А.Л. Журавлев, Т.А. Нестик, И.В. Никитенко // Человеческий фактор: проблемы психологии и эргономики. — 2009. — № 4. - С. 8-12.

4. Крапивская Л.В. Личность и её ценностные ориентации/ Л.В. Крапивская. - М. 1983.

5. Король 0.Ф. Представления о типе собственной культуры в межкультурном взаимодействии сотрудников организаций (на примере Республики Крым / 0.Ф. Король // Проблемы современного педагогического образования. Сер. Педагогика и психология. Сб. статей: - Ялта: РИО ГПА, 2018. - Вып.60. Ч. І. - C. $451-455$.

6. Король 0.Ф. Ценностные предпочтения в межкультурном взаимодействии сотрудников организации / 0.Ф. Король. // Проблемы современного педагогического образования. Сер. Педагогика и психология. Сб. статей: - Ялта: РИО ГПА, 2018. - Вып. 61. - Ч. ІІ. - С.300-307. 
7. Ладанов И.Д. Психология управления рыночными структурами: преобразующее лидерство / И.Д. Ладанов. - М.: УЦ «Перспектива», 1997. - С.155.

8. Леонтьев Д.А. Ценностные представления в индивидуальном и групповом сознании / Д.А. Леонтьев // Психологическое обозрение. - 1998. -№1. C. $15-25$.

9. Мамедова Ж.С. Ценностные ориентации в культуре личности/Ж.С. Мамедова. - Межвузовский сборник научных трудов. «Российское общество: цивилизованные горизонты трансформации». Выпуск 1. Саратов, 2004. - С.96-100.

10. Мамедова Ж.С. Ценностные ориентации личности в контексте временной перспективы/Ж.С. Мамедова. - Гуманитарные и социально-экономические науки. Спецвыпуск «Педагогика». Ростов-на-Дону, издательство РГПУ, 2006. С.121- 132.

11. Немов Р.С. Психология. Учебник для студентов педагогических учебных заведений/ Р.С. Немов. - М.: Владос, 1998. $-470 c$.

12. Ольшанский В.Б. Личность и социальные ценности/ В.Б. Ольшанский. - М.: Мысль, 1966. - Т.1.- 530 с.

13. Практическая психодиагностика. Методики и тесты / [ред. Д.Я. Райгородский]. - Самара: Издательский Дом «БАХРАХ», 1998. - 672 с.

14. Ценностные ориентации личности как система с многомерной структурой / С.С. Бубнова, В.Ю. Крылов // Психол. наука: Традиции, соврем. Состояние и перспективы: Тези докл. науч.конф. ин-та психол. РАН., ( М., $28-30$ янв., 1997г.). - М., 1997. -С.48 - 49.

15. Шейн Э. Организационная культура и лидерство/ Э. Шейн. - СПб.: Изд. Питер, 2002. - С. 31-32.

16. Шольц А. Организационная культура: между иллюзией и реальностью / А. Шольц // Проблемы теории и практики управления. - 1995. - №3. - С.110115.

17. Ядов В.А. Диспозиционная концепция личности / В.А. Ядов // Социальная психология в трудах отечественных психологов. - СПб.: Питер, 2000. - С.76-93.

18. Яницкий М.С. Ценностные ориентации личности как динамическая система / М.С Яницкий. - М., 1997. - 592 с.

19. Hofstede G. Cultural Constraints in Management Theories// Academy of Management Executive.1993.Vol.7.№ 1.

20. Rokeach M. Beliefs, Attitudes, and Values.-San Francisco, Josey-Bass Co, 1972. - 214 p.

() Король Ольга Феликсовна (korololga2008@gmail.com).

Журнал «Современная наука: актуальные проблемы теории и практики»

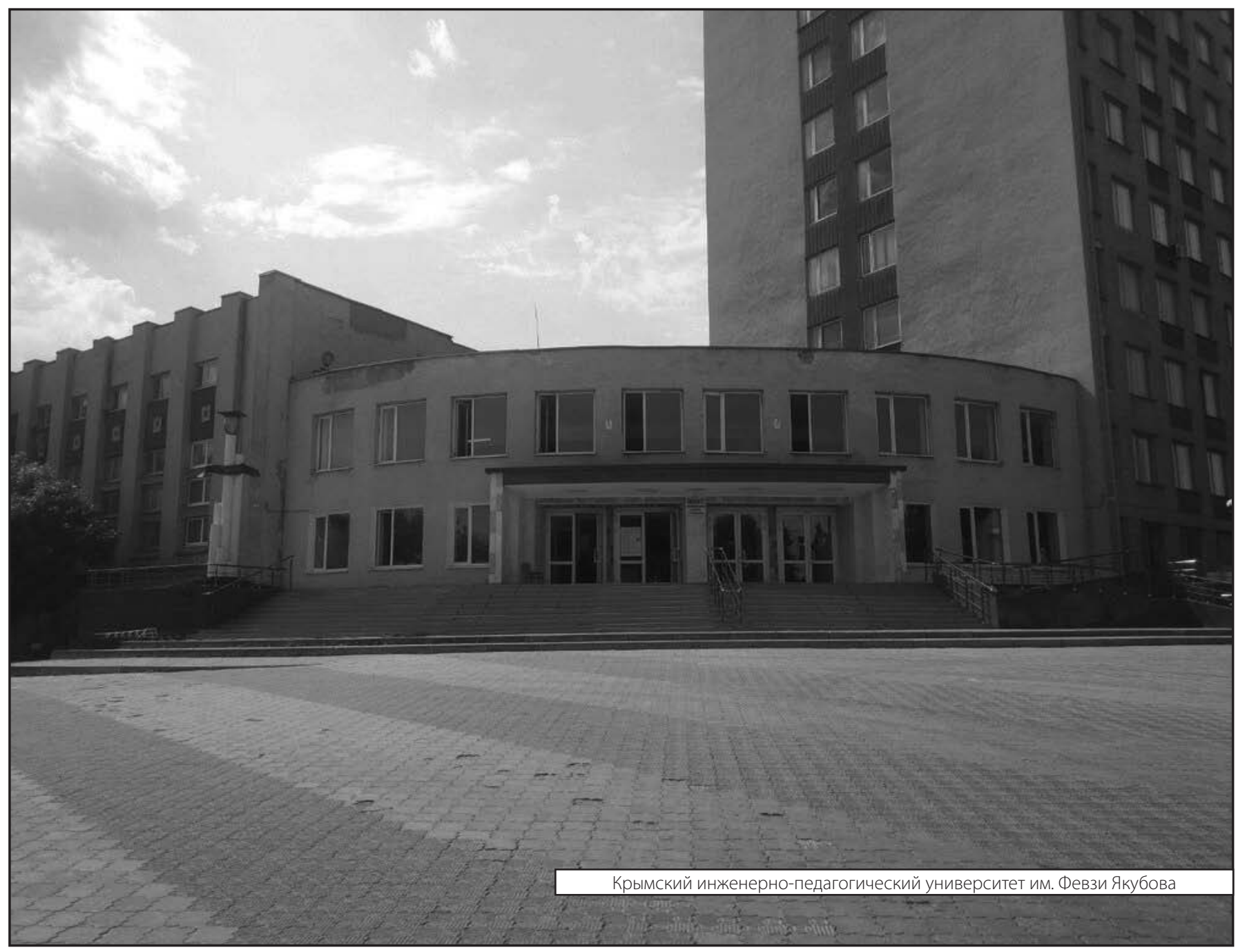

